\title{
A Highly Efficient Nonfullerene Acceptor with Sulfonyl-Based Ending Groups
}

Lupiao Tao ${ }^{\mathrm{a}, \mathrm{b}}$, Xiaohui Liu ${ }^{\mathrm{c}}$, Changbo Deng ${ }^{\mathrm{a}}$, Wenjun Zhang ${ }^{\mathrm{a}, \mathrm{b}}$, Weijie Songa,b

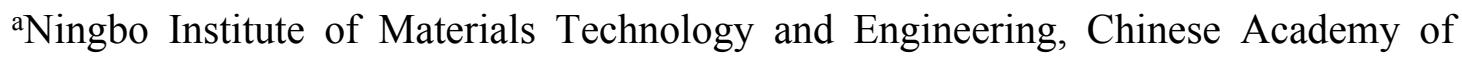
Sciences, Ningbo 315201, China.

${ }^{b}$ Center of Materials Science and Optoelectronics Engineer, University of Chinese Academy of Sciences, Beijing 100049, China.

'School of Physical Science and Technology, Ningbo University, Ningbo 315211, China

\section{Experimental Section}
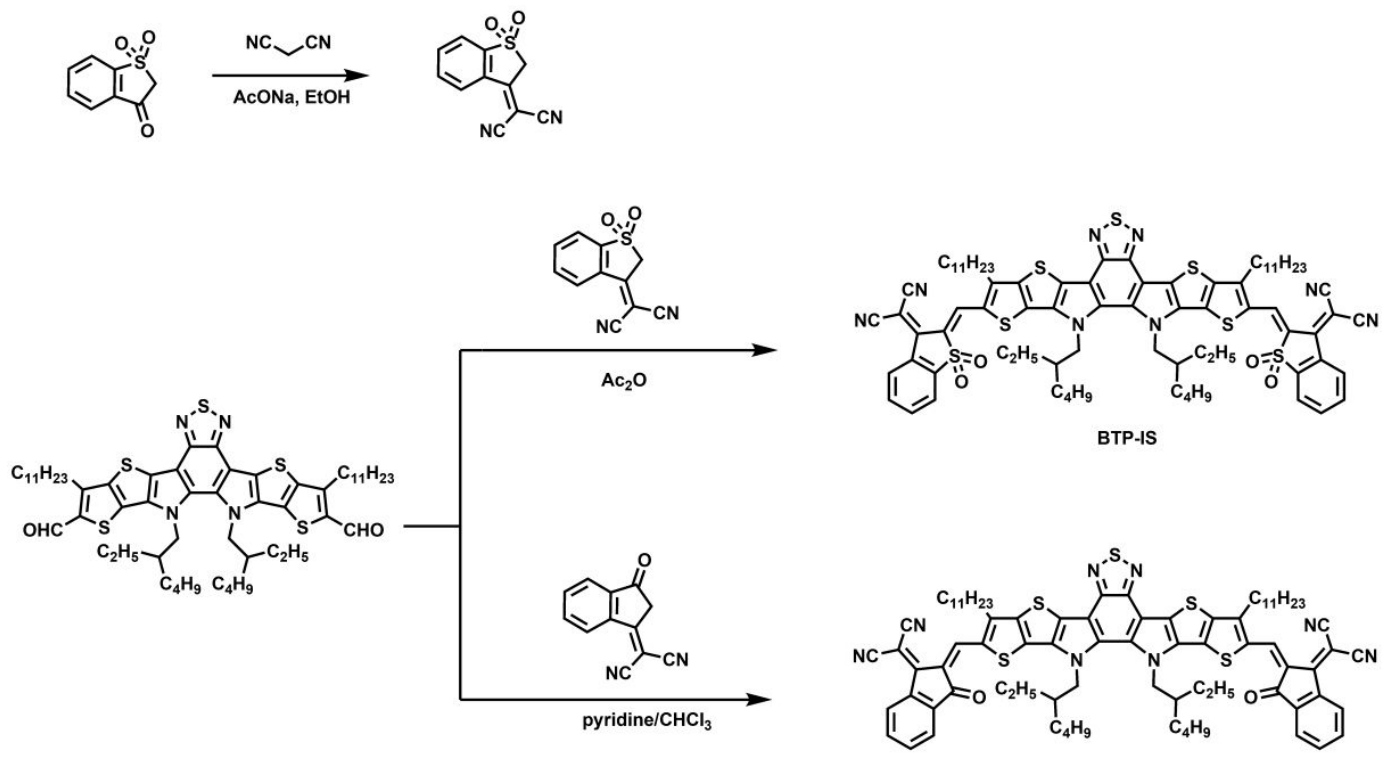

BTP-IC

Scheme S1. Synthetic routes of BTP-IS and BTP-IC

\section{Characterizations}

${ }^{1} \mathrm{H}$ NMR and ${ }^{13} \mathrm{C}$ NMR spectra were measured on a Bruker Advance III $400 \mathrm{MHz}$ and $100 \mathrm{MHz}$ spectrometer respectively and using tetramethylsilane (TMS) as internal standard at ambient temperature. Mass spectra were recorded on a Finnigan LCQ mass spectrometer. UV-vis spectra were recorded on the GS54T spectrophotometer (Shanghai Lengguang Technology Co, China). Thermogravimetric analysis (TGA) was carried out on a PerkinElmer Diamond TG/DTA instrument at a heating rate of $20{ }^{\circ} \mathrm{C}$ $\mathrm{min}^{-1}$ under a $\mathrm{N}^{2}$ atmosphere with temperature from 30 to $789^{\circ} \mathrm{C}$. Cyclic voltammetry was conducted on a CHI660D electrochemical workstation in a deoxygenated anhydrous acetonitrile solution of tetrabutylammonium hexafluorophosphate (n- 
$\left.\mathrm{Bu}_{4} \mathrm{NPF}_{6}, 0.1 \mathrm{M}\right)$ under a nitrogen atmosphere with a saturated $\mathrm{Ag} / \mathrm{AgCl}$ as the reference electrode. Transmission electron microscopy (TEM) were recorded by using field emission scanning electron microscope (Tecnai F20, FEI, America) at $7 \mathrm{kV}$ accelerating voltage. The surface roughness was tested by atomic force microscopy (AFM) (Dimension 3100, Vecco, America). The steady-state photoluminescence (PL) spectra were conducted by a fluorescence spectrophotometer (FL3-111, HORIBA, French). The current density-voltage $(J-V)$ characteristics were measured under simulated AM 1.5G irradiation $\left(100 \mathrm{~mW} \mathrm{~cm}^{-2}\right)$ by Keithley 2440 sourcemeter in a glovebox. The external quantum efficiency (EQE) was conducted by a Newport EQE system (ORIEL IQE 200TM) in the atmosphere.

\section{Device Fabrication}

The ITO substrates were successively cleaned by sonication of $15 \mathrm{~min}$ in detergent, deionized water, acetone and isopropyl alcohol before being dried in a nitrogen stream. The cleaned ITO substrates were then treated with Oxygen-Plasma for $5 \mathrm{~min}$. PEDOT:PSS was spin-coated onto ITO substrates at $4000 \mathrm{rpm}$ for $60 \mathrm{~s}$, and then annealed on a hot plate at $140{ }^{\circ} \mathrm{C}$ in the air for $10 \mathrm{~min}$. Then the substrates were transferred into argon-filled glovebox for spin-coating of organic active layer. The active layer solutions were prepared by co-dissolving PM6 and acceptors in chloroform while stirring at $40{ }^{\circ} \mathrm{C}$ overnight. The concentration, donor:acceptor (D:A) ratio and volume ratio of 1-chloronaphthalene $(\mathrm{CN})$ were optimized sequentially. Active layers were spun cast in the glovebox, and annealed at optimized temperature and time. Subsequently, a $\mathrm{ZnO}$ nanoparticle solution $(8 \mathrm{mg} / \mathrm{mL}$ in 2,2,2-trifluoroethanol) was deposited on the active layers at $3000 \mathrm{rpm}$ for $30 \mathrm{~s}$. At last, $100 \mathrm{~nm}$ of Al was deposited through a shadow mask (defined the active area of the devices $0.09 \mathrm{~cm}^{2}$ ) onto the interfacial layer by thermo-evaporation in a vacuum chamber with base pressure $1 \times 10^{-6}$ mbar. 


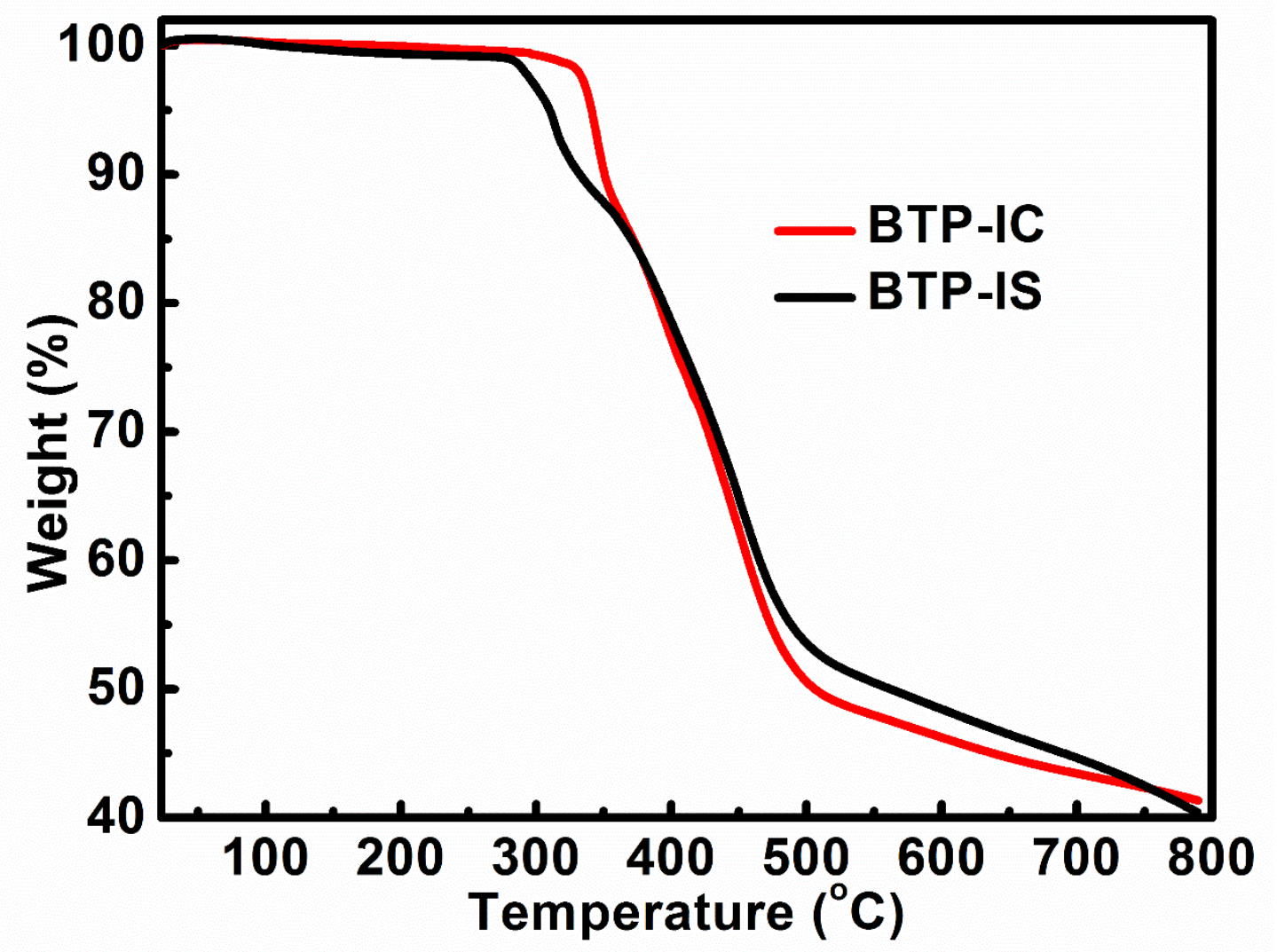

Figure S1. Thermalgravimetric analysis (TGA) curves of BTP-IC and BTP-IS. 

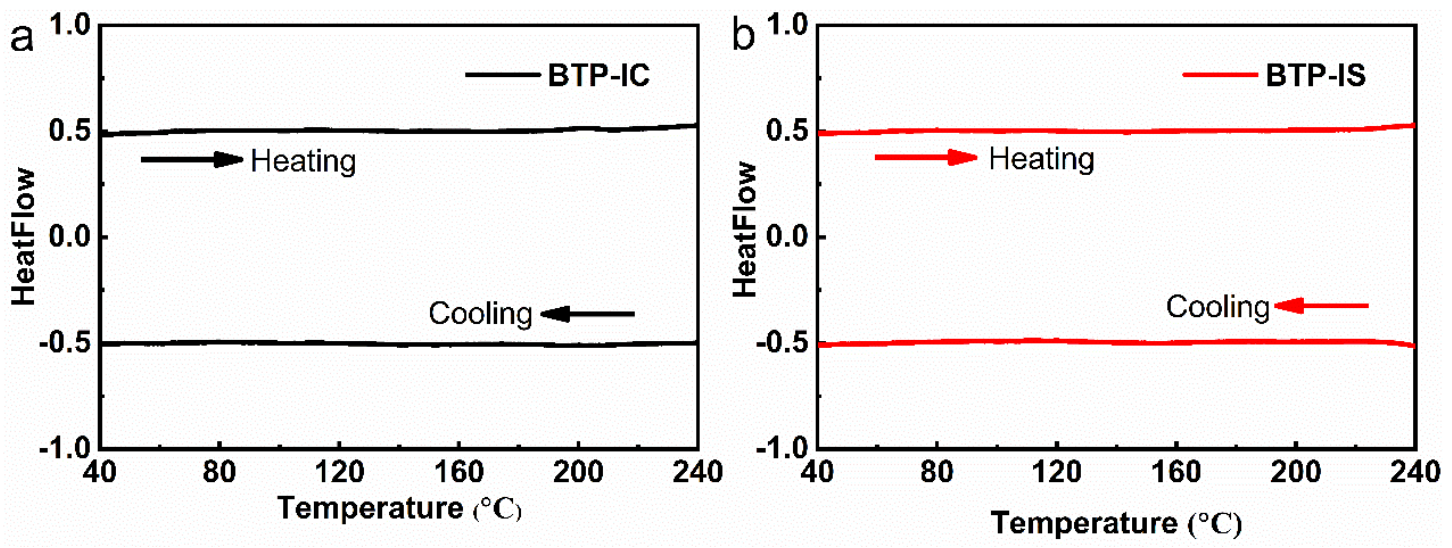

Figure S2. DSC heating and cooling curves of BTP-IC (a) and BTP-IS (b). 


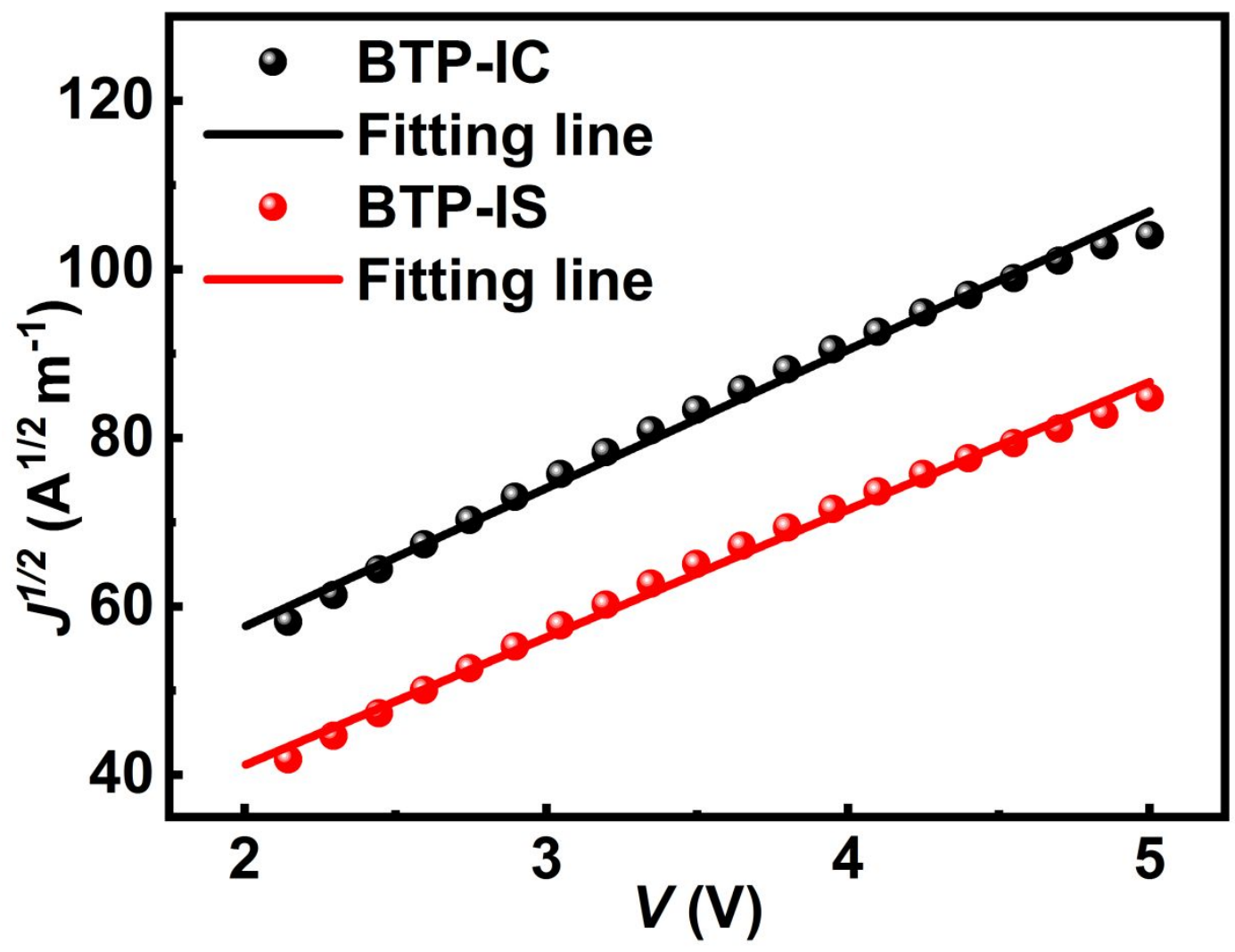

Figure S3. $J^{1 / 2}-V$ curves of the electron-only devices (ITO/ZnO/BTP-IC or BTPIS/ZnO/Al). 

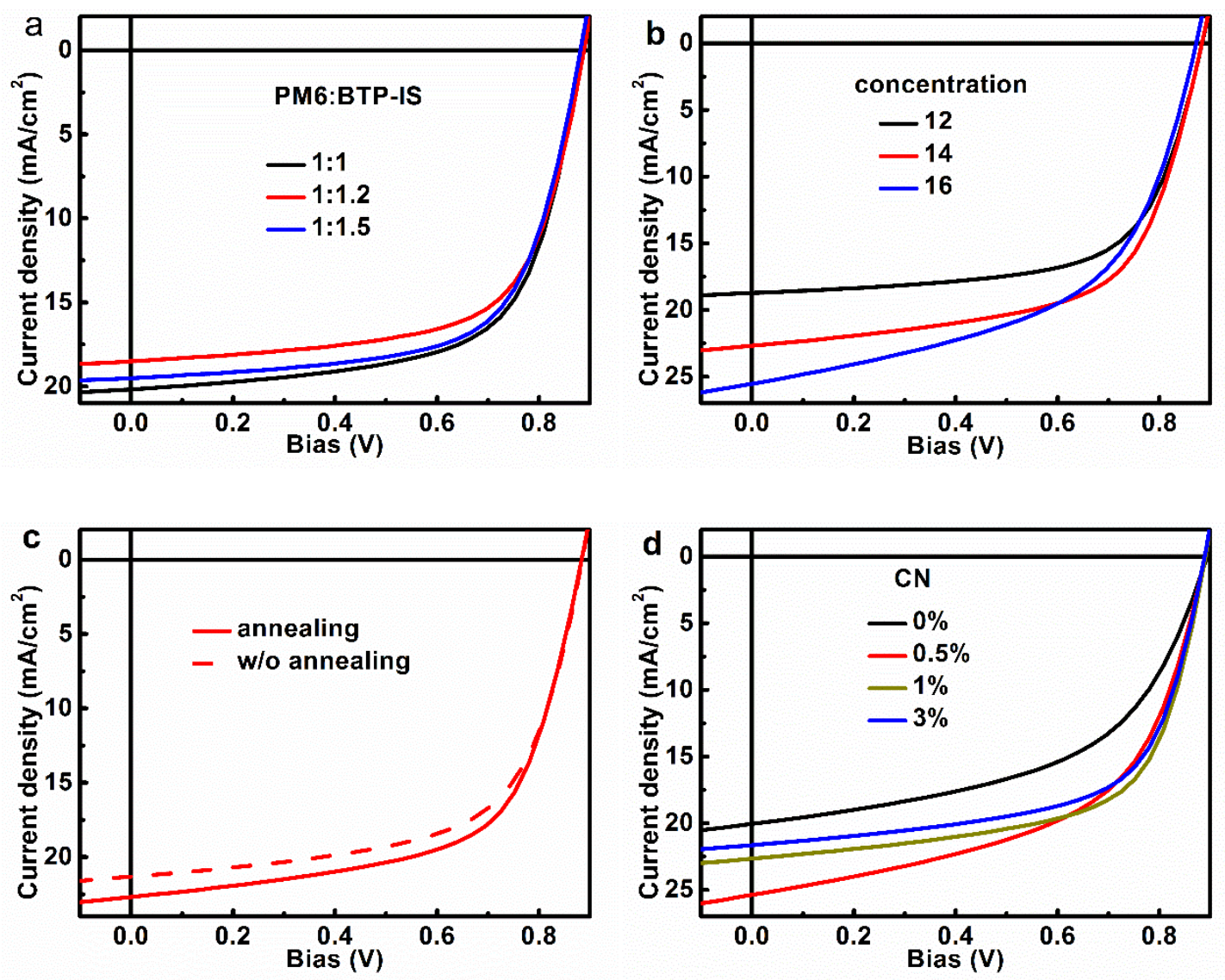

Figure S4. $J-V$ curves of BTP-IS device with different ratio(a), concentration(b), additive ratio(d), with or without annealing(c). The annealing temperature is $100{ }^{\circ} \mathrm{C}$ and the time is $10 \mathrm{~min}$.

Table S1. Device parameters of the BTP-IS-Based devices with different donor:acceptor ratios (total concentration of $16 \mathrm{mg} / \mathrm{mL}$ ) under the illumination of AM $1.5 \mathrm{G}, 100 \mathrm{~mW} / \mathrm{cm}^{2}$.

\begin{tabular}{cllll}
\hline PM6:BTP-IS & $\begin{array}{l}V_{O C} \\
(\mathrm{~V})\end{array}$ & $\begin{array}{l}J_{S C} \\
\left(\mathrm{~mA} / \mathrm{cm}^{2}\right)\end{array}$ & $\begin{array}{l}F F \\
(\%)\end{array}$ & $\begin{array}{l}\text { PCE } \\
(\%)\end{array}$ \\
\hline \multirow{2}{*}{$1: 1$} & $0.884^{\mathrm{a}}$ & 20.14 & 64.89 & 11.56 \\
& $\left(0.883^{\mathrm{b}}\right)$ & $(19.49)$ & $(64.50)$ & $(11.10)$ \\
\hline \multirow{2}{*}{$1: 1.2$} & 0.884 & 18.71 & 65.46 & 10.82 \\
& $(0.884)$ & $(18.56)$ & $(65.35)$ & $(10.73)$ \\
\hline \multirow{2}{*}{$1: 1.5$} & 0.881 & 19.48 & 65.7 & 11.28 \\
& $(0.878)$ & $(19.28)$ & $(65.53)$ & $(11.10)$ \\
\hline
\end{tabular}

${ }^{\mathrm{a}}$ The best parameter; ${ }^{b}$ the average value calculated from 4 devices 
Table S2. Device parameters of the BTP-IS-Based devices with different donor:acceptor (1:1.2) concentrations under the illumination of AM 1.5 G, 100 $\mathrm{mW} / \mathrm{cm}^{2}$.

\begin{tabular}{cllll}
\hline $\begin{array}{c}\text { Concentration } \\
(\mathrm{mg} / \mathrm{mL})\end{array}$ & $\begin{array}{l}V_{O C} \\
(\mathrm{~V})\end{array}$ & $\begin{array}{l}J_{S C} \\
\left(\mathrm{~mA} / \mathrm{cm}^{2}\right)\end{array}$ & $\begin{array}{l}F F \\
(\%)\end{array}$ & $\begin{array}{l}\text { PCE } \\
(\%)\end{array}$ \\
\hline \multirow{2}{*}{12} & $0.884^{\mathrm{a}}$ & 18.71 & 65.46 & 10.82 \\
& $\left(0.884^{\mathrm{b}}\right)$ & $(18.56)$ & $(65.35)$ & $(10.73)$ \\
\hline \multirow{2}{*}{14} & 0.883 & 22.66 & 62.18 & 12.45 \\
& $(0.885)$ & $(22.49)$ & $(61.89)$ & $(12.32)$ \\
\hline \multirow{2}{*}{16} & 0.872 & 25.50 & 53.77 & 11.96 \\
& $(0.872)$ & $(25.12)$ & $(53.25)$ & $(11.66)$ \\
\hline
\end{tabular}

${ }^{a}$ The best parameter; ${ }^{b}$ the average value calculated from 4 devices

Table S3. Device parameters of the BTP-IS-Based devices with or without annealing $\left(100^{\circ} \mathrm{C}\right)$ under the illumination of $\mathrm{AM} 1.5 \mathrm{G}, 100 \mathrm{~mW} / \mathrm{cm}^{2}$.

\begin{tabular}{clcll}
\hline \multirow{2}{*}{ Annealing } & $\begin{array}{l}V_{O C} \\
(\mathrm{~V})\end{array}$ & $\begin{array}{c}J_{S C} \\
\left(\mathrm{~mA} / \mathrm{cm}^{2}\right)\end{array}$ & $\begin{array}{l}F F \\
(\%)\end{array}$ & $\begin{array}{l}\text { PCE } \\
(\%)\end{array}$ \\
\hline \multirow{2}{*}{ w/o } & $0.884^{\mathrm{a}}$ & 21.29 & 62.23 & 11.72 \\
& $\left(0.882^{\mathrm{b}}\right)$ & $(21.49)$ & $(61.20)$ & $(11.60)$ \\
\hline \multirow{2}{*}{$\mathrm{w}$} & 0.883 & 22.66 & 62.18 & 12.45 \\
& $(0.885)$ & $(22.49)$ & $(61.89)$ & $(12.32)$ \\
\hline
\end{tabular}

${ }^{\mathrm{a}}$ The best parameter; ${ }^{\mathrm{b}}$ the average value calculated from 4 devices

Table S4. Device parameters of the BTP-IS-Based devices with different volumes of 1chloronaphthalene $(\mathrm{CN})$ under the illumination of AM $1.5 \mathrm{G}, 100 \mathrm{~mW} / \mathrm{cm}^{2}$.

\begin{tabular}{cllll}
\hline $\begin{array}{c}\text { CN volume } \\
(\%)\end{array}$ & $\begin{array}{l}V_{O C} \\
(\mathrm{~V})\end{array}$ & $\begin{array}{c}J_{S C} \\
\left(\mathrm{~mA} / \mathrm{cm}^{2}\right)\end{array}$ & $\begin{array}{l}F F \\
(\%)\end{array}$ & $\begin{array}{c}\text { PCE } \\
(\%)\end{array}$ \\
\hline \multirow{2}{*}{0} & $0.892^{\mathrm{a}}$ & 20.03 & 52.74 & 9.43 \\
& $\left(0.889^{\mathrm{b}}\right)$ & $(20.05)$ & $(51.96)$ & $(9.26)$ \\
\hline \multirow{2}{*}{0.5} & 0.889 & 25.35 & 54.55 & 12.30 \\
& $(0.888)$ & $(24.47)$ & $(54.69)$ & $(11.88)$ \\
\hline \multirow{2}{*}{1} & 0.890 & 22.63 & 63.45 & 12.79 \\
& $(0.884)$ & $(21.39)$ & $(65.23)$ & $(12.34)$ \\
\hline \multirow{2}{*}{3} & 0.889 & 21.62 & 63.15 & 12.13 \\
& $(0.888)$ & $(20.42)$ & $(66.50)$ & $(12.04)$ \\
\hline
\end{tabular}

${ }^{a}$ The best parameter; ${ }^{b}$ the average value calculated from 6 devices 

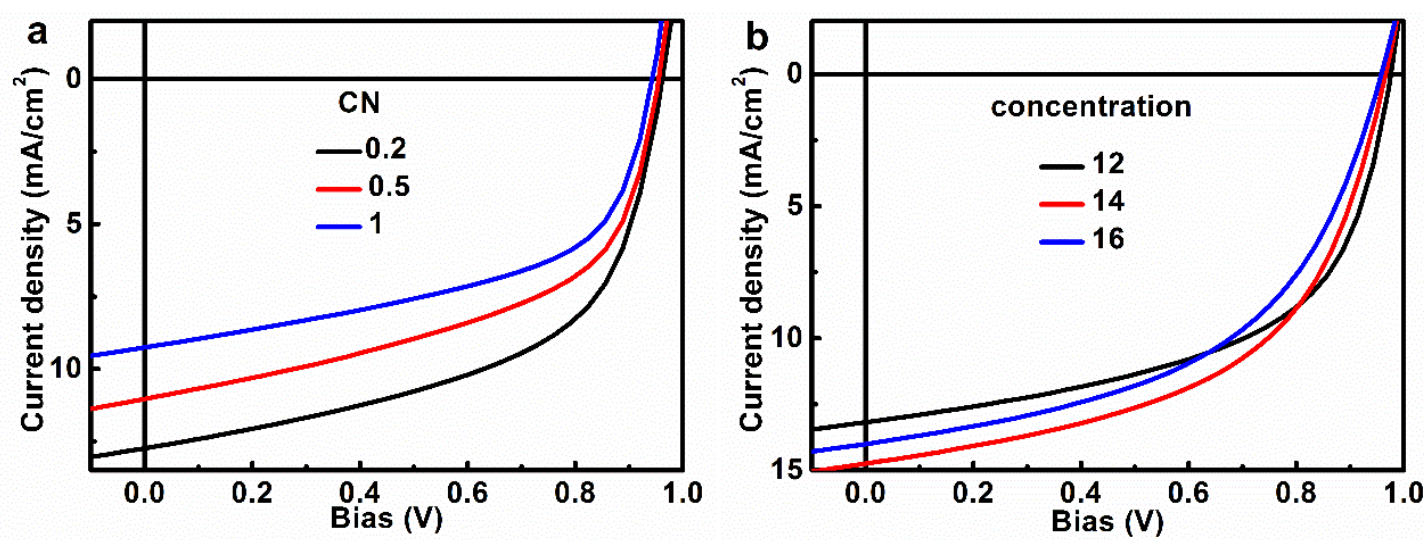

Figure S5. J-V curves of BTP-IC device with different volumes of $\mathrm{CN}$ (a) and donor:acceptor (1:1.2) concentrations (b).

Table S5. Device parameters of the BTP-IC-Based devices with different volumes of 1-chloronaphthalene $(\mathrm{CN})$ under the illumination of AM $1.5 \mathrm{G}, 100 \mathrm{~mW} / \mathrm{cm}^{2}$.

\begin{tabular}{clcll}
\hline $\begin{array}{c}\text { CN volume } \\
(\%)\end{array}$ & $\begin{array}{l}V_{O C} \\
(\mathrm{~V})\end{array}$ & $\begin{array}{c}J_{S C} \\
\left(\mathrm{~mA} / \mathrm{cm}^{2}\right)\end{array}$ & $\begin{array}{l}F F \\
(\%)\end{array}$ & $\begin{array}{l}\text { PCE } \\
(\%)\end{array}$ \\
\hline \multirow{2}{*}{0.2} & $\begin{array}{l}0.961^{\mathrm{a}} \\
\left(0.964^{\mathrm{b}}\right)\end{array}$ & $\begin{array}{l}12.72 \\
(12.46)\end{array}$ & $\begin{array}{l}54.9 \\
(53.18)\end{array}$ & $\begin{array}{l}6.72 \\
(6.39)\end{array}$ \\
\hline \multirow{2}{*}{0.5} & 0.955 & 11.03 & 52.2 & 5.50 \\
& $(0.929)$ & $(10.70)$ & $(43.32)$ & $(4.33)$ \\
\hline \multirow{2}{*}{1} & 0.943 & 9.25 & 54.0 & 4.71 \\
& $(0.937)$ & $(7.10)$ & $(48.78)$ & $(3.27)$ \\
\hline
\end{tabular}

a The best parameter; ${ }^{b}$ the average value calculated from 6 devices

Table S6. Device parameters of the BTP-IC-Based devices with different donor:acceptor (1:1.2) concentrations under the illumination of AM 1.5 G, 100 $\mathrm{mW} / \mathrm{cm}^{2}$.

\begin{tabular}{clcll}
\hline $\begin{array}{c}\text { Concentration } \\
(\mathrm{mg} / \mathrm{mL})\end{array}$ & $\begin{array}{l}V_{O C} \\
(\mathrm{~V})\end{array}$ & $\begin{array}{c}J_{S C} \\
\left(\mathrm{~mA} / \mathrm{cm}^{2}\right)\end{array}$ & $\begin{array}{l}F F \\
(\%)\end{array}$ & $\begin{array}{l}\text { PCE } \\
(\%)\end{array}$ \\
\hline \multirow{2}{*}{12} & $0.973^{\mathrm{a}}$ & 13.16 & 55.7 & 7.13 \\
& $\left(0.971^{\mathrm{b}}\right)$ & $(13.13)$ & $(55.33)$ & $(7.06)$ \\
\hline \multirow{2}{*}{14} & 0.964 & 14.72 & 53.1 & 7.54 \\
& $(0.967)$ & $(14.32)$ & $(52.73)$ & $(7.30)$ \\
\hline \multirow{2}{*}{16} & 0.956 & 13.97 & 50.8 & 6.78 \\
& $(0.957)$ & $(13.55)$ & $(50.58)$ & $(6.56)$ \\
\hline
\end{tabular}

${ }^{a}$ The best parameter; ${ }^{b}$ the average value calculated from 6 devices 


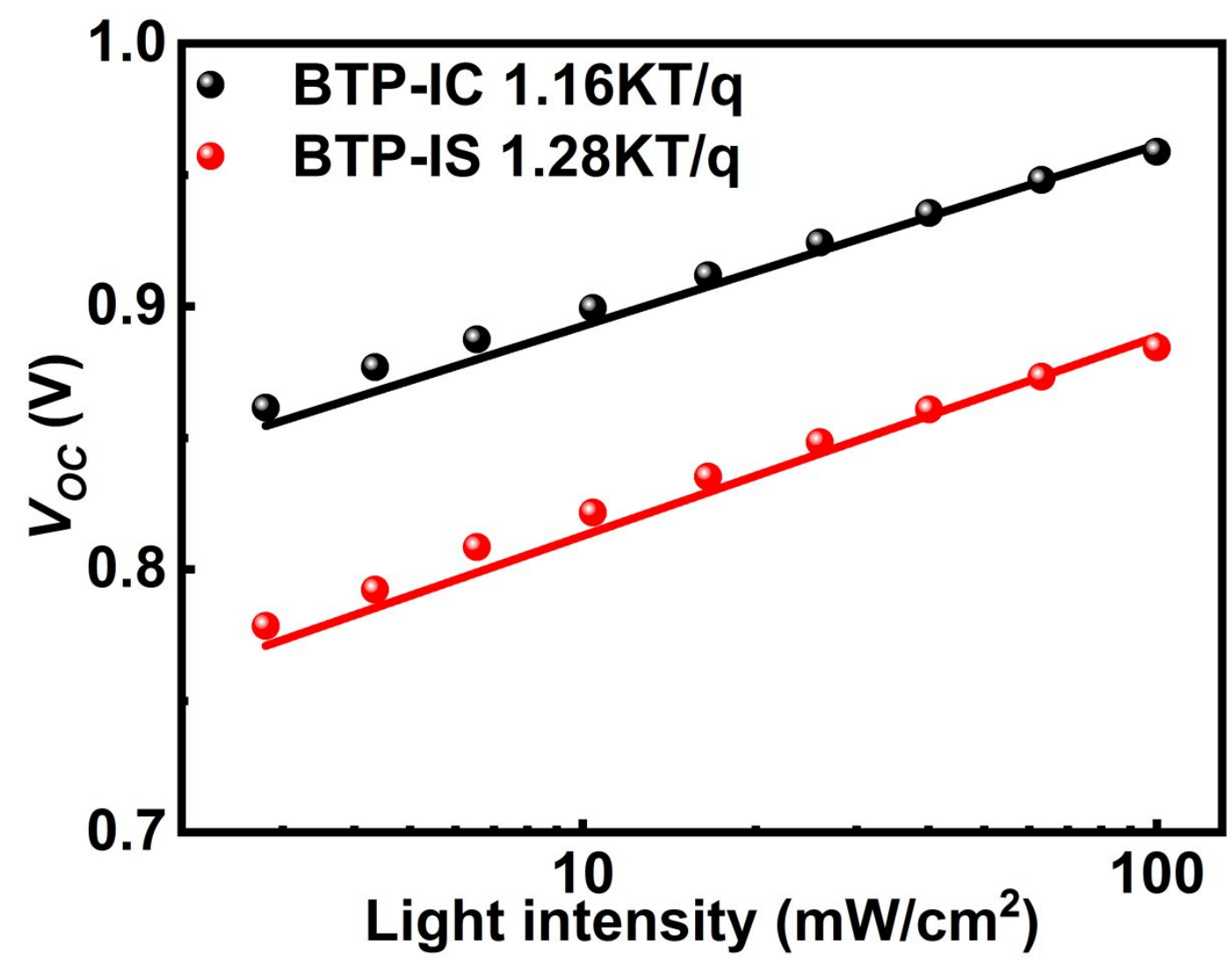

Figure S6. Plot of $\mathrm{V}_{\mathrm{OC}}$ versus light intensity for BTP-IC device and BTP-IS device. 

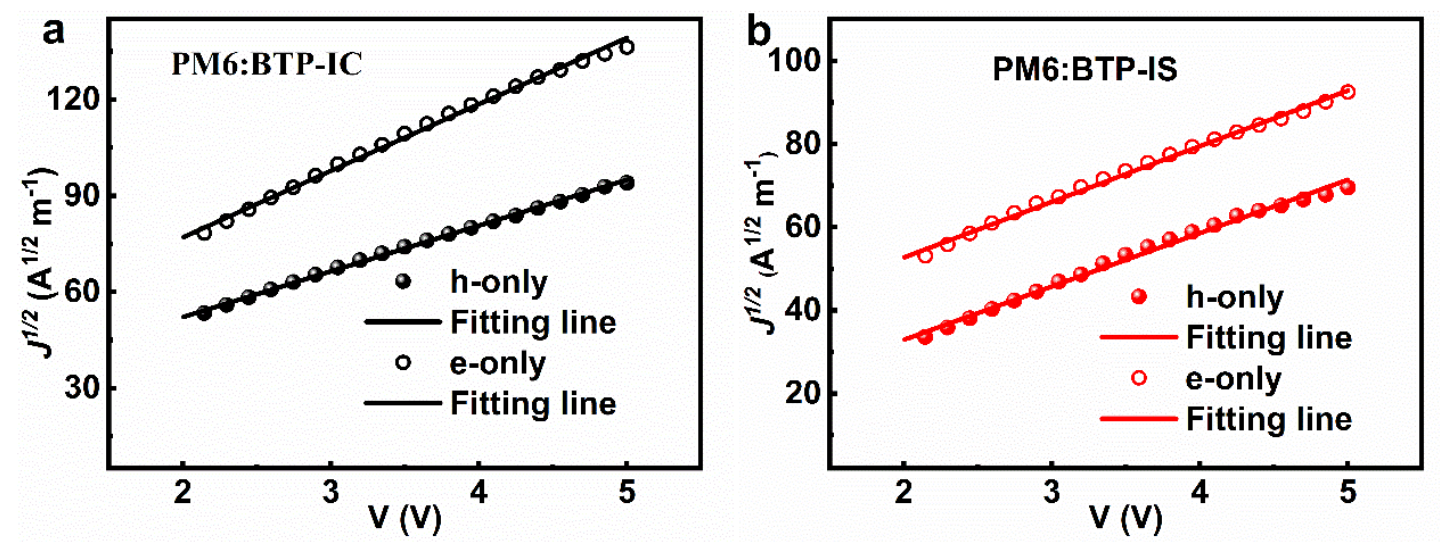

Figure S7. $J^{1 / 2}-V$ curves of the hole-only (ITO/PEDOT:PSS/activelayer/Au) and electron-only devices (ITO/ZnO/activelayer/ZnO/Al) with PM6:BTP-IC (a) or PM6:BTP-IS (b) as activelayer. 


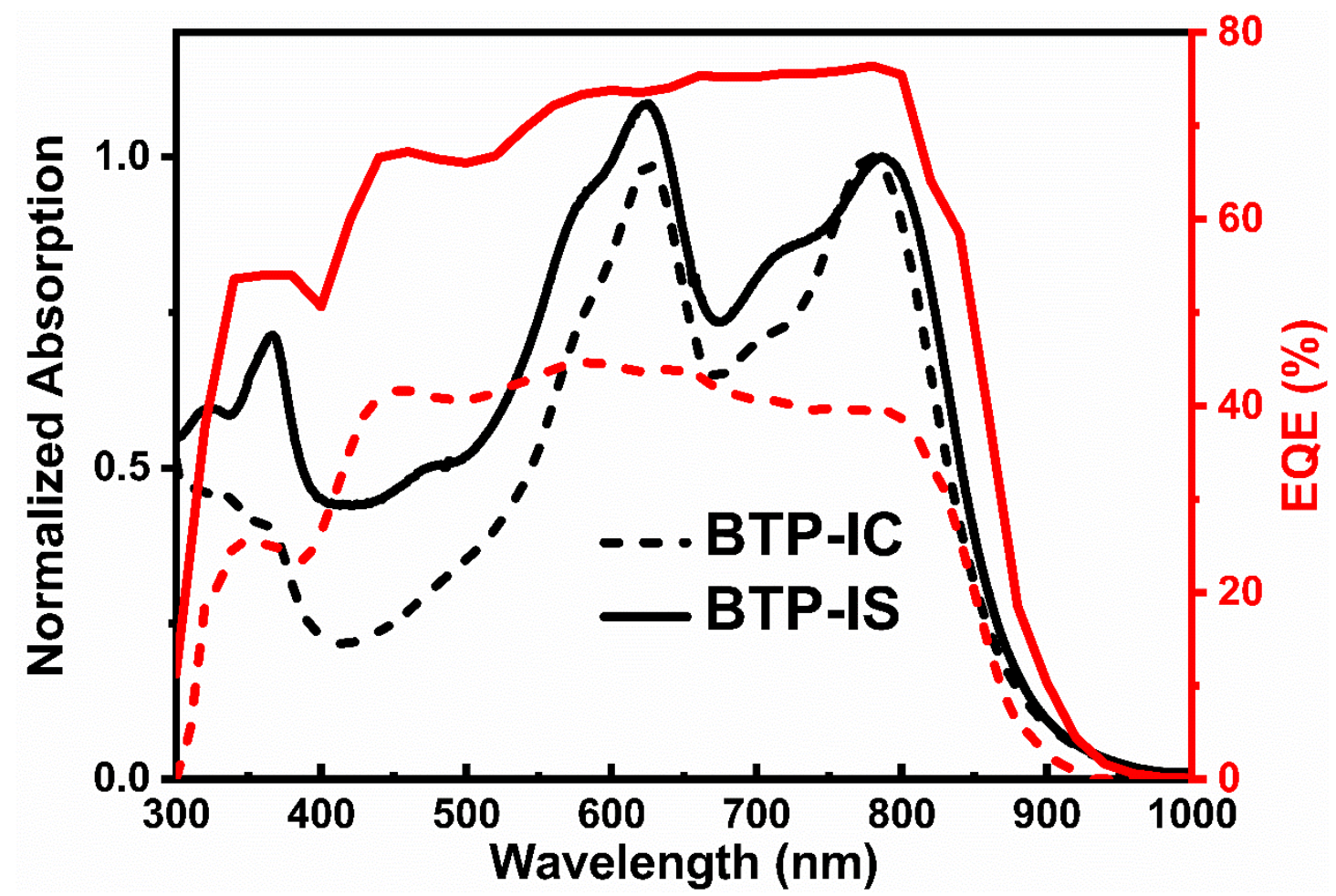

Figure S8. Normalized absorption spectra of PM6:BTP-IC and PM6:BTP-IS blend films and EQE spectra of the optimal devices. 

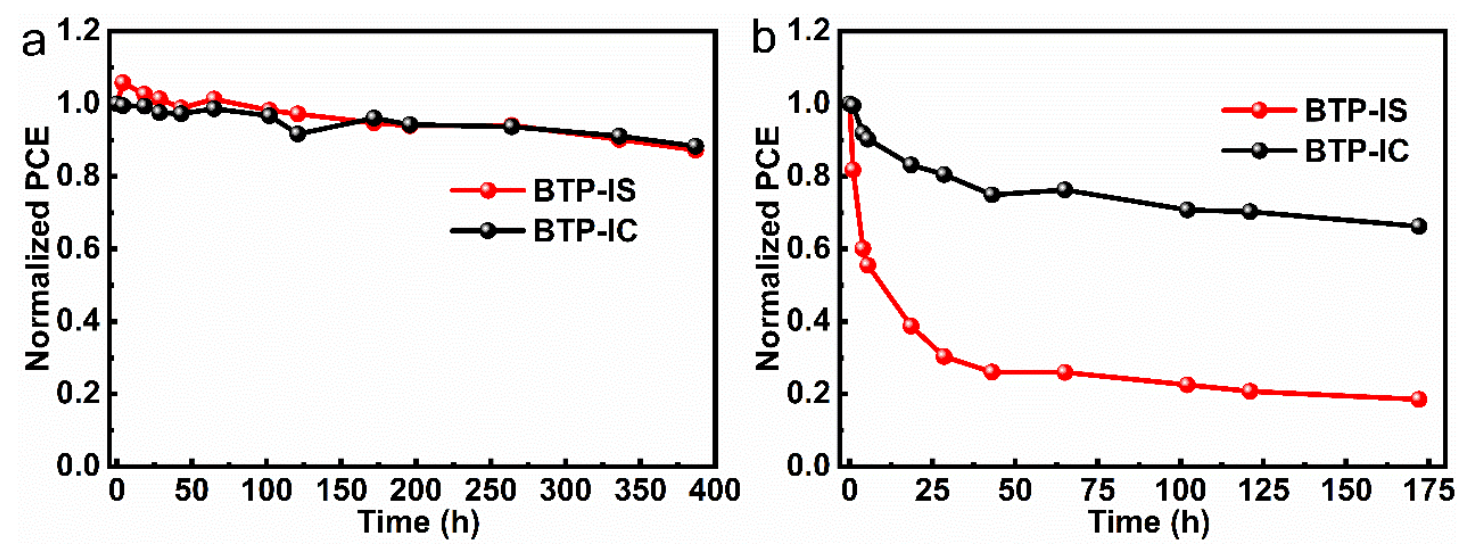

Figure S9. (a) Normalized PCEs of devices in a glove box filled with nitrogen; (b) Thermal stability of OSCs sequentially stored at $80^{\circ} \mathrm{C}$ in glove box.

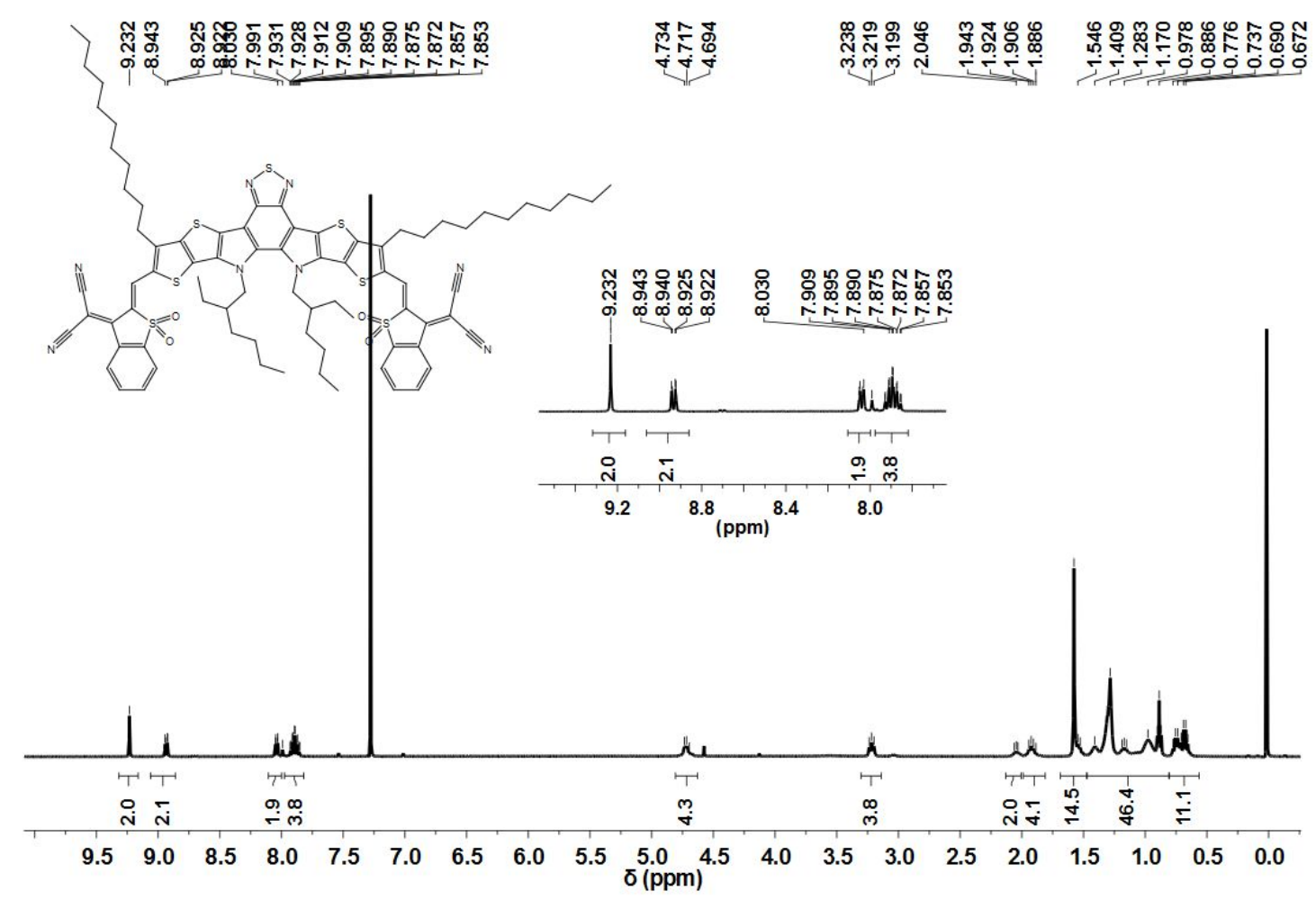

Figure S10. ${ }^{1} \mathrm{H}$ NMR spectra of BTP-IS 


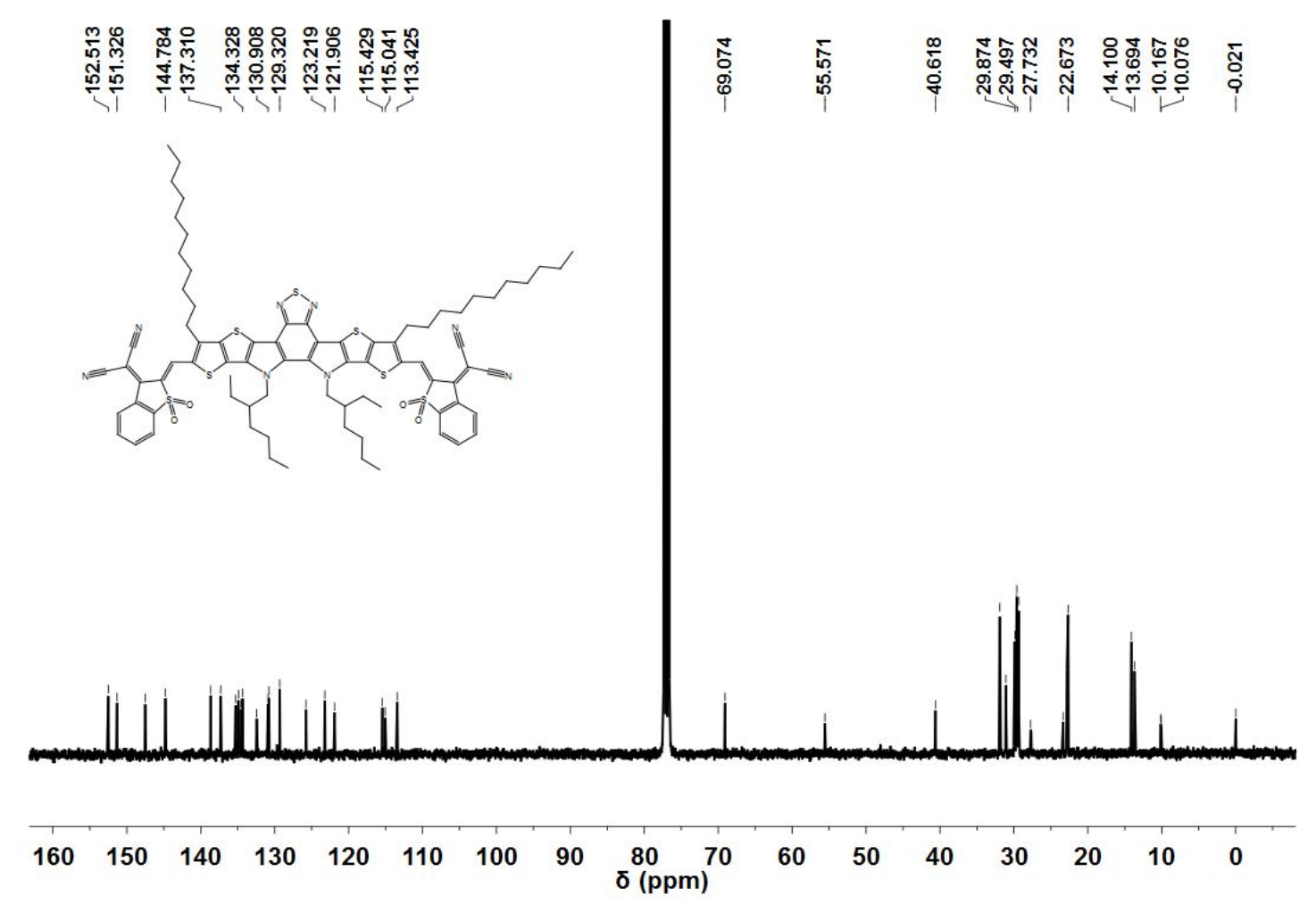

Figure S11. ${ }^{13} \mathrm{C}$ NMR spectra of BTP-IS

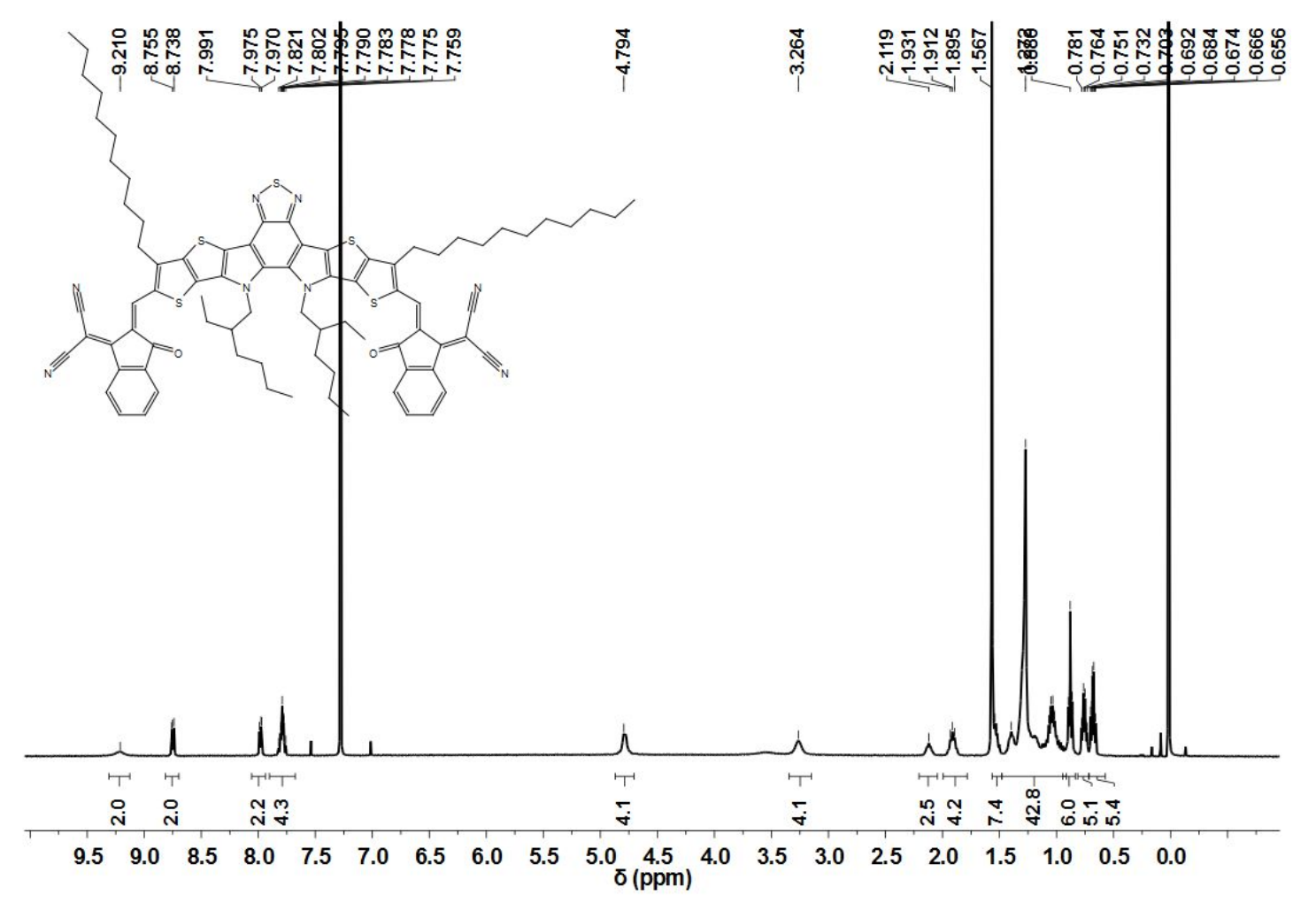

Figure S12. ${ }^{1} \mathrm{H}$ NMR spectra of BTP-IC 


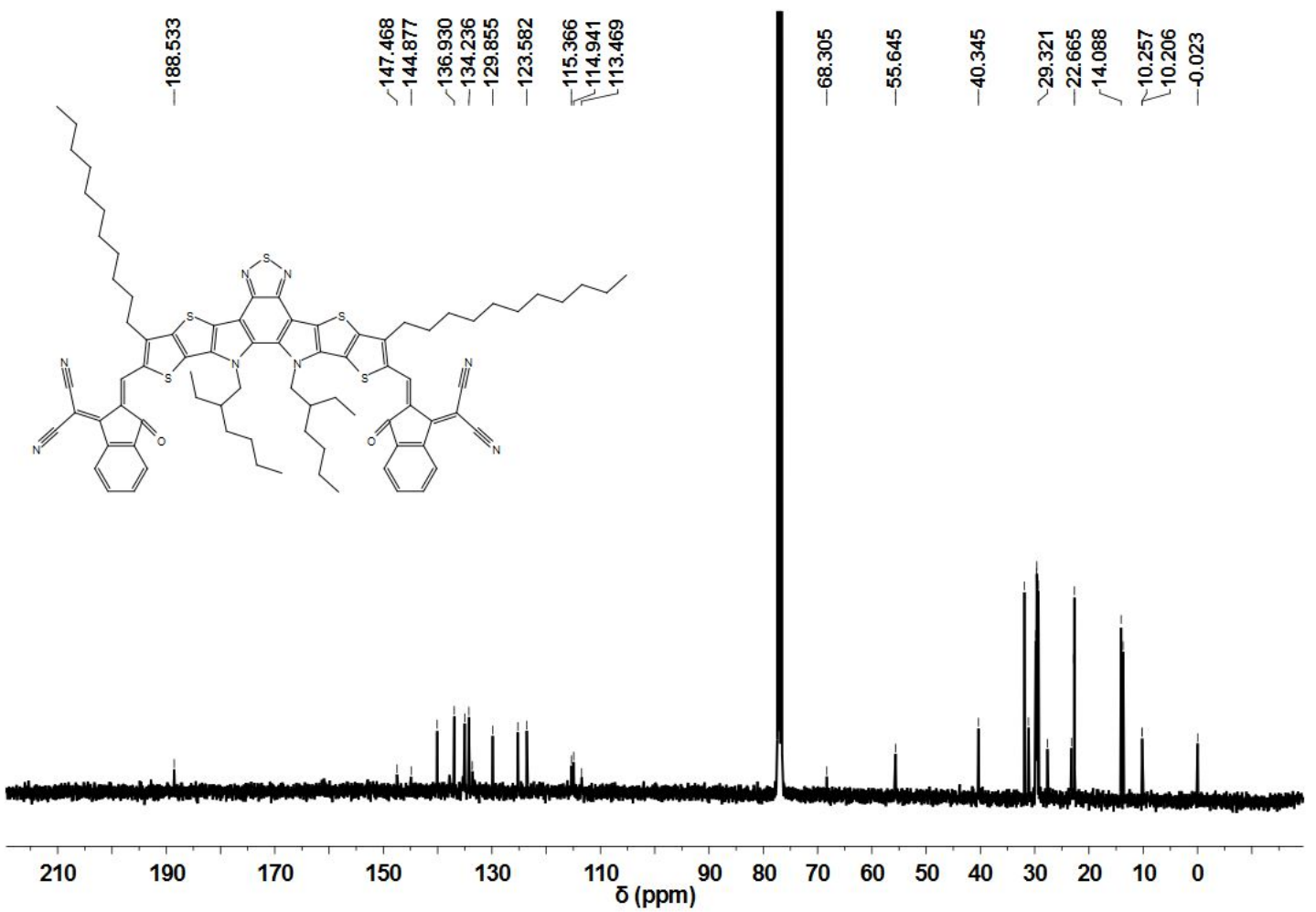

Figure S13. ${ }^{13} \mathrm{C}$ NMR spectra of BTP-IC 